\title{
Partial Dopamine Depletion of the Prefrontal Cortex Leads to Enhanced Mesolimbic Dopamine Release Elicited by Repeated Exposure to Naturally Reinforcing Stimuli
}

\author{
John B. Mitchella and Alain Gratton \\ Douglas Hospital Research Center, Department of Psychiatry, McGill University, Montreal, Quebec, Canada H4H 1R3, \\ and Center for Studies in Behavioral Neurobiology, Concordia University, Montreal, Quebec, Canada H3G 1M8
}

\begin{abstract}
High-speed chronoamperometry was used to monitor the extracellular concentration of dopamine within the nucleus accumbens, a terminal field of the mesolimbic dopamine system, in freely behaving rats exposed daily, on 6 consecutive days, to one of two naturally reinforcing stimuli; a highly palatable food or sex-related olfactory cues. The animals either were intact or had previously received microinjections of 6-hydroxydopamine into prefrontal cortex to lesion dopamine terminals. Food reliably elicited increases in dopamine levels within the nucleus accumbens, and if prefrontal cortical dopamine had been depleted, the response to food increased with repeated testing. Animals exposed to the sexually relevant olfactory stimulus showed progressively enhanced dopamine release with repeated testing, and this enhancement was potentiated by prefrontal cortical dopamine depletion. These results indicate that repeated exposure to naturally reinforcing events can lead to a hyperresponsiveness of the mesolimbic dopamine system upon future activation, and suggest that the dopamine projection to prefrontal cortex exerts an indirect, inhibitory influence on mesolimbic dopamine neurotransmission.
\end{abstract}

The results of a number of pharmacological studies have indicated that mesencephalic dopaminc (DA) is involved in the motivational processes underlying feeding and sexual behaviors. Destruction of mesencephalic DA cells by treatment with the catecholamine neurotoxin 6-hydroxydopamine (6-OHDA) produces aphagia (Ungerstedt, 1971) and deficits in sexual behaviors (Caggiula et al., 1976). The systemic administration of DA antagonists decreases feeding in a manner consistent with DA antagonism inhibiting the motivational component of feeding (Blundell and Latham, 1978; Wise et al., 1978; Geary and Smith, 1985). The administration of the psychomotor stimulant amphetamine directly into mesolimbic terminal fields facilitates feeding (Evans and Vaccarino, 1986; Wise et al., 1989). Similarly, the display of sexual behaviors by both castrated and gonadally intact males can be facilitated by a variety of treat-

\footnotetext{
Received Dec. 30, 1991; revised Apr. 6, 1992; accepted Apr. 17, 1992

This research was supported by grants from the Natural Sciences and Engineering Research Council of Canada (NSERCC) and les Fonds pour la Formation de Chercheurs et l'Aide à la Recherche du Québec (FCAR) to A.G. A.G. is a NSERCC University Research Scholar.

Correspondence should be addressed to Dr. Alain Gratton, Douglas Hospital Research Center, 6875 LaSalle Boulevard, Verdun, Quebec, Canada H4H 1 R3.

"Present address: Department of Psychology, McGuinn Hall, Boston College, Chestnut Hill, MA 02167.
}

Copyright (C) 1992 Society for Neuroscience $0270-6474 / 92 / 123609-10 \$ 05.00 / 0$ ments that increase or enhance dopaminergic neurotransmission, and is inhibited by DA antagonists (Butcher et al., 1969; Malmnas, 1973, 1976, 1977; Foreman and Hall, 1987). The administration of opiates to the region of mesolimbic DA cell bodies increases the firing frequency of a population of A 10 neurons (Gysling and Wang, 1983) and increases DA metabolism in mesolimbic terminal fields (Kalivas et al., 1983). Similar injections of opiates and opioid peptides into the region of mesencephalic DA cells elicit feeding (Mucha and Iversen, 1986; Hamilton and Bozarth, 1988) and facilitate stimulation-induced feeding (Jenck et al., 1986), and can also facilitate sexual behaviors, especially indices of sexual arousal (Mitchell and Stewart, 1990).

Electrical stimulation can also elicit or facilitate both feeding and sexual behaviors. Electrical stimulation of the medial forebrain bundle, a fiber tract connecting midbrain and forebrain structures, elicits feeding (Glickman and Schiff, 1967) and sexual behavior (Vaughan and Fisher, 1962; Caggiula and Hoebel, 1966). When applied directly to the region of the mesolimbic DA cell bodies, electrical stimulation will elicit feeding (Cox and Valenstein, 1969; Gratton and Wise, 1988) and copulation (Eibergen and Caggiula, 1973).

Direct assessment of the activity of mesolimbic DA system activity accompanying cxposure to incentive-motivational stimuli has come from studies that have measured the concentrations of DA, or DA metabolites, in mesolimbic terminal fields concomitant with exposure to food or sexual stimuli. Intraoral infusions and feeding among both food-deprived and food-sated rats increase extracellular DA concentrations within the nucleus accumbens ( $\mathrm{nAcc}$ ), a major mesolimbic DA system terminal field (Hernande $<$ and Hoebel, 1988; Rose and Gratton, 1990; Mark et al., 1991). Similarly, the concentrations of DA and DA metabolites in the $\mathrm{nAcc}$ are increased when measured during or after copulation (Mitchell and Stewart, 1989; Pfaus et al., 1989; Mas et al., 1990). Recently, we reported that exposure to sexually relevant olfactory cues, alone, increased the extracellular concentrations of DA within the nAcc (Mitchell and Gratton, 1991), suggesting that sex-related olfactory cues, without the intense locomotor activation that accompanies copulation, can activate the mesolimbic DA system. Thus, electrical and pharmacological activation of the mesolimbic DA system facilitates feeding and sexual behaviors, and exposure to both feeding and sex-related stimuli increases activity within the mesolimbic DA system.

Repeated exposure to pharmacological agents known to increase extracellular concentrations of DA, such as psychomotor 
stimulants (Kuczenski, 1983) and opiates (Gysling and Wang, 1983), leads to an increased, or sensitized, behavioral response (Babbini et al., 1975; Post, 1980; Vezina and Stewart, 1984; Kalivas et al., 1985) and enhanced DA release (Peris and Zahniser, 1987; Robinson et al., 1988) upon subsequent pharmacological activation. Repeated exposure to sex-related olfactory cues can also lead to progressively increased extracellular concentrations of DA (Mitchell and Gratton, 1991), suggesting that naturally reinforcing events, not only pharmacological intervention, can result in hyperresponsiveness of the mesolimbic DA system upon future activation. Whether or not a sensitized response of the mesolimbic DA system can be obtained with food has not been explored.

The Al0 cell group also contains DA cells that innervate cortical, rather than limbic, targets (Bjorklund and Lindvall, 1984). The prefrontal cortex (PFC), a terminal field of the mesocortical DA system, in turn projects to the nAcc (Beckstead, 1979). Evidence from several sources suggests that the mesocortical DA system functions, in part, in opposition to mesolimbic DA. For example, DA receptor activation within the PFC suppresses self-stimulation of the medial forebrain bundle (Olds, 1990), and damage to the PFC potentiates amphetamineinduced locomotion (Adler, 1961; Lynch et al., 1969; Iversen, 1971). Increased concentrations of DA within the PFC decrease extracellular concentrations of the DA metabolite dihydroxyphenylacetic acid (DOPAC) within the nAcc, and DA antagonists applied to the PFC increase concentrations of DOPAC within the nAcc (Louilot et al., 1989). Thus, separate A10 DA cells project to the PFC and to the $\mathrm{nAcc}$, and DA within the PFC acts indirectly to dampen mesolimbic DA neurotransmission (Spence et al., 1985), providing an inhibitory cortical control over limbic output. Whether the mesocortical DA system regulates the mesolimbic DA response to naturally occurring stimuli, such as food and sex-related cues, has not been explored.

In the present study, high-speed chronoamperometry with monoamine-selective voltammetric electrodes (Gerhardt et al., 1984, 1986; Nagy et al., 1985) was used to monitor changes in extracellular levels of amines in the nAcc. Animals were tested repeatedly with either a highly palatable food or with sex-related olfactory cues. The use of a highly palatable food avoided the necessity of food deprivation, and the use of sex-related olfactory cues, bedding from cages that housed estradiol-progesterone-primed female rats, avoided any contribution from the intense locomotor activity that accompanies copulatory exposure to an estrus female conspecific. Furthermore, some animals exposed to each of these stimuli had previously undergone 6-OHDA lesions of the PFC. Thus, these experiments allowed for tests of initial and potentially sensitized DA release within the $\mathrm{nAcc}$ elicited by naturally reinforcing events, and examined the contribution of mesocortical DA in modulating mesolimbic DA release.

\section{Materials and Methods}

\section{Subjects}

Long-Evans male rats (Charles River, St. Constant, Quebec, Canada), weighing 275-320 gm, were used. Subjects were selected from a larger population on the basis of two tests of copulatory behavior; only those males that mounted within 20 min of the introduction of the female, and ejaculated within $30 \mathrm{~min}$ of the first intromission on both tests were included as subjects.

Female rats were ovariectomized under methoxyflurane anesthesia (Pitman-Moore, Mississauga, Ontario, Canada). Estrus was induced by injections of $10 \mu \mathrm{g}$ of estradiol benzoate (Sigma, St. Louis, MO), sub- cutaneously, in $0.1 \mathrm{ml}$ of peanut oil 72 and $24 \mathrm{hr}$ before use, and 0.5 $\mathrm{mg}$ of progesterone (Sigma), subcutaneously, in $0.2 \mathrm{ml}$ of peanut oil 4$5 \mathrm{hr}$ prior to use in copulation tests and $6-7 \mathrm{hr}$ before bedding was collected (sce below)

All animals were housed in plastic cages lined with bedding and had Purina Rat Chow and water available ad libitum. The animal colony was maintained on a $12 \mathrm{hr}$ light/12 hr dark reverse light cycle with lights off at 0800 .

\section{Stereotaxic surgery}

6-OHDA lesions. Subjects were injected with $0.6 \mathrm{mg} / \mathrm{kg}$ (i.p.) atropine sulfate (Abbott Laboratories, Montreal) and anesthetized with sodium pentobarbital $(60 \mathrm{mg} / \mathrm{kg}$, i.p.; Nembutal, Abbott), and $30-45 \mathrm{~min}$ prior to 6-OHDA infusion were treated with $25 \mathrm{mg} / \mathrm{kg}$ desipramine (Research Biochemicals Inc., Natick, MA). With the incisor bar adjusted to maintain the skull between bregma and lambda horizontal, an injection cannula was inserted into the medial prefrontal cortex $3.5 \mathrm{~mm}$ anterior to bregma and $0.8 \mathrm{~mm}$ lateral of the midline (Paxinos and Watson, 1982). Consecutive injections were made at three dorsal/ventral sites 1.0, 2.0, and $3.0 \mathrm{~mm}$ below the surface of the brain. At each injection site, $4 \mu \mathrm{g}$ of 6-OHDA (expressed as salt; Sigma) was injected in a volume of $1 \mu \mathrm{l}$ of $0.4 \%$ ascorbic acid over $2 \mathrm{~min}$. The injection cannula was left in place for $2 \mathrm{~min}$ after cach injection to allow diffusion of the toxin away from the cannula tip. Animals were tested 4-6 weeks after lesioning.

Electrode placement. Subjects were injected with $0.6 \mathrm{mg} / \mathrm{kg}$ (i.p.) atropine sulfate and anesthetized with sodium pentobarbital $(60 \mathrm{mg} / \mathrm{kg}$, i.p.). Animals were placed in a stereotaxic frame with the incisor bar adjusted to maintain the skull between bregma and lambda horizontal. An electrochemical probe, an $\mathrm{Ag} / \mathrm{AgCl}$ reference electrode and a stainless steel ground wire were implanted in each animal. The coordinates for the electrochemical probe were $1.6 \mathrm{~mm}$ anterior to bregma, $1.6 \mathrm{~mm}$ lateral of the midline (ipsilateral to the PFC lesion), and $7.4 \mathrm{~mm}$ below the surface of the brain (Paxinos and Watson, 1982). The reference and ground wires were implanted in parietal cortex. The electrodes and connector were secured by dental acrylic and anchored to five stainless steel screws embedded in the skull. Testing commenced $2 \mathrm{~d}$ after surgery.

\section{In vivo electrochemical methods}

The electrochemical probe consisted of three $30-\mu \mathrm{m}$-diameter carbon fibers (Avco Specialty Materials, Lowell, MA) extending 50-70 $\mu \mathrm{m}$ beyond the tip of a pulled glass capillary. The carbon fibers were coated with a $5 \%$ solution of the anionic polymer Nafion (Aldrich, Milwaukee, WI). Immediately before implanting, each electrode was calibrated for its sensitivity to DA and characterized for its selectivity for DA against ascorbic acid. All calibrations were performed in $0.1 \mathrm{M}$ phosphatebuffered saline (pH 7.4) that contained $250 \mu \mathrm{M}$ ascorbic acid to mimic brain extracellular levels. Only electrodes exhibiting a high degree of linearity $(r \geq 0.997)$ in response to increasing concentrations of DA and displaying a DA to ascorbic acid selectivity ratio of at least 1000 to 1 were used.

Electrochemical recordings were obtained using a microcomputercontrolled high-speed chronoamperometric apparatus (IVEC 5, Medical Systems Corp., Greenvale, NY). A $+0.55 \mathrm{~V}$ pulse, versus the reference electrode, was applied to the electrochemical probe at a rate of $5 \mathrm{~Hz}$. The oxidation current was digitally integrated during the last $80 \mathrm{msec}$ of the $100 \mathrm{msec}$ pulse. The average of five oxidative cycles of the chronoamperometric waveform was graphically displayed on a video monitor at the rate of $0.5 \mathrm{~Hz}$. The reverse current flow (reduction current) generated by the reduction of the oxidized electroactive species was digitized in the same manner when the potential was returned to its resting level $(0.0 \mathrm{~V}$ for $100 \mathrm{msec})$. The changes in the electrochemical signal were cxpressed as nanomolar changes from baseline by using the calibration factor determined for each electrode for DA during the in vitro calibration.

\section{Testing}

Animals were tested in a $35 \mathrm{~cm} \times 38 \mathrm{~cm} \times 65-\mathrm{cm}$-high chamber made from $1.25-\mathrm{cm}$-thick plywood that had a Plexiglass front panel. The chambers were housed in a box lined with sound-attenuating tiles and lit by a $40 \mathrm{~W}$ red light bulb. The floor of the testing chamber was covered with absorbent paper. Subjects were given two $2 \mathrm{hr}$ habituation sessions to the testing chamber prior to having an electrochemical probe implanted. During a testing session, the animal was connected to the chronoamperometric apparatus via a shielded cable and a low-impedance 
multichannel commutator (Airflyte, Bayonne, $\mathrm{NJ}$ ). In order to minimize extraneous electrical interference, the primary signal amplifier was situated at the end of the shielded cable, connecting directly onto the animal's electrode connector.

Two stimuli were presented to the animals, a highly palatable food ( $1.7 \mathrm{gm}$ of Froot Loops breakfast cereal, Kellogg's) and bedding obtained from cages that housed estrus female rats. The bedding was collected immediately prior to use and was removed after $15 \mathrm{~min}$. The amount of food presented and the length of time the bedding was left in the chamber were chosen to produce changes in the electrochemical signal of comparable duration and amplitude, during initial exposure. The stimuli were placed in the center of the recording chamber after 10-15 min of stable baseline was obtained, and the electrochemical signal was allowed to return to baseline before recording was stopped. Animals were tested daily during the animals' dark cycle, between 0830 and 1300 hr. The chamber floor was cleaned between animals.

On day 1 of testing, animals were presented with both the food and the bedding, in random order. On days 2-5 of testing, animals were presented with only the food or the bedding. Animals were retested on day 6 with both stimuli, presented in random order. Additional groups of animals were placed, daily, in the recording chambers but were not presented with either the food or the bedding. Animals in these groups were left in the recording chamber for a length of time approximating the average test session length among the food- and bedding-exposed groups.

At the conclusion of testing, animals were decapitated and the brains rapidly removed. The brains were transected $1.0-1.5 \mathrm{~mm}$ anterior to the electrode track, and the anterior section, containing the PFC, was frozen on dry ice for later determination of amine content, while the posterior section, containing the nAcc, was placed in $10 \%$ formalin. The PFC was sliced in $250 \mu \mathrm{m}$ sections and the medial PFC removed using the Palkovits microdissection punch technique (Palkovits and Brownstein, 1988). High-performance liquid chromatography with electrochemical detection was used to determine monoamine content in the medial PFC using assay procedures published previously (Doherty and Gratton, 1991). The formalin-fixed posterior brain section was sliced in $25 \mu \mathrm{m}$ sections for histological determination of electrode tip location.

\section{Measures and statistics}

Digitized values of the basal oxidative current were obtained $20 \mathrm{~min}$ after each animal was placed into the testing chamber, prior to obtaining baseline recordings for the day's testing. The basal oxidative current varies across electrodes; in order to compensate for this, the basal current of each animal was expressed as the percentage of the current recorded on tcst day 1 and analyzed using analysis of variance. After obtaining the resting oxidation current, changes in oxidative current were monitored and automatically converted to nanomolar changes in DA levels using the calibration factor for DA determined in vitro for each electrode prior to implantation. Three measures were obtained during the test session: the rate of increase, peak amplitude, and the reduction to oxidation current ratio (Red:Ox ratio) of the increase. The rate of increase, expressed as $\mathrm{nm} / \mathrm{sec}$, from the initial change in the electrochemical signal-to-peak amplitude was analyzed to assess responsiveness. Peak amplitude of the signal was defined as the highest point, in nanomolar concentration, recorded during exposure to the stimulus. The Red:Ox ratio was calculated at the point at which the change in the electrochemical signal reached asymptote and was used to identify the contributors to the increase in the electrochemical signal. All measures were analyzed using analysis of variance (Myers, 1979) and analysis of simple effects (Winer, 1971).

\section{Results}

\section{Tests with food}

Two groups of animals were tested with a highly palatable food, intact animals (Intact-Food; $n=7$ ) and animals that had previously received 6-OHDA lesions of the PFC (Lesion-Food; $n$ $=6$ ). The use of a highly palatable food avoided potentially confounding factors associated with food deprivation (see Carlson et al., 1987) and allowed for experimenter control over when the animals would eat. As mentioned earlier, all animals were tested with both food and bedding on the first and sixth test day. An additional group of intact (Intact-Control, $n=6$ ) and

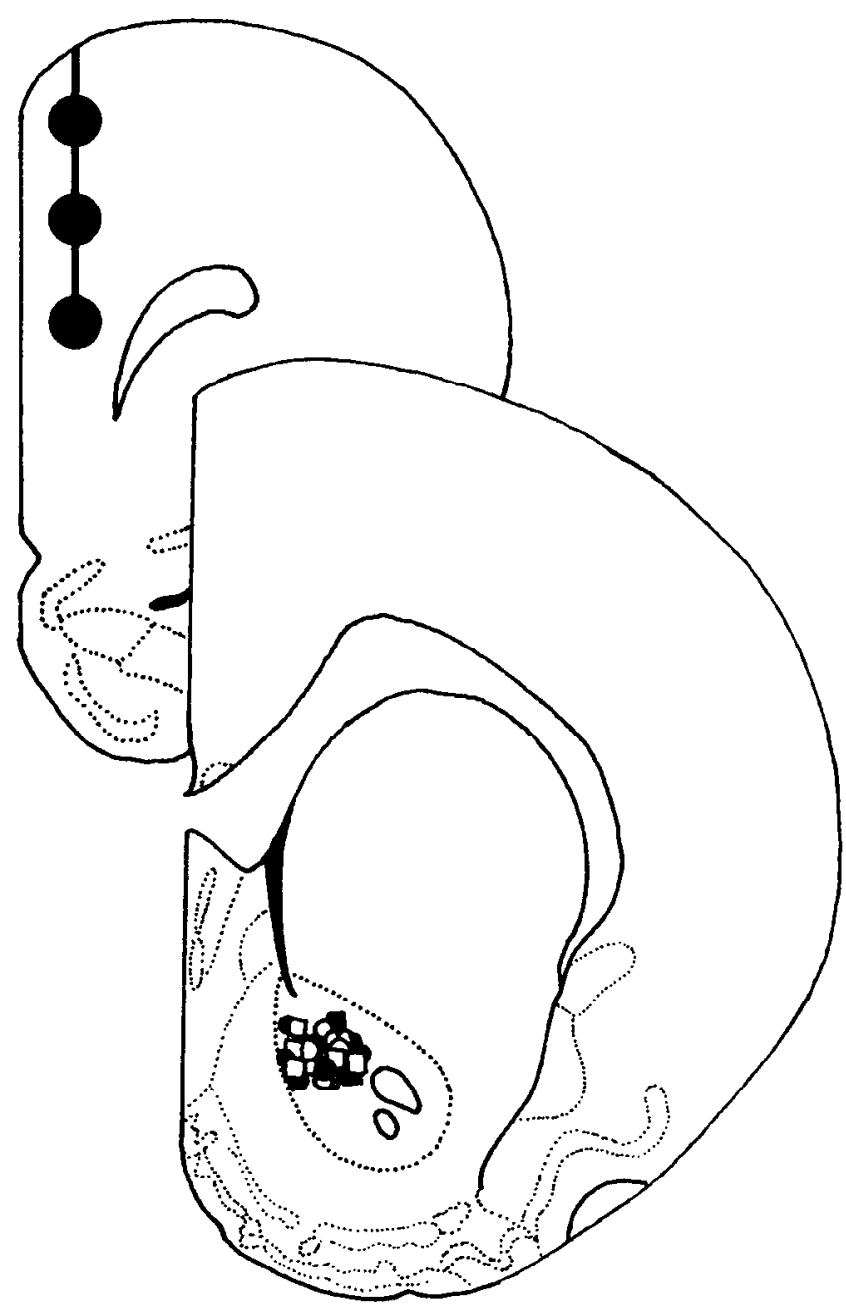

Figure 1. Location of the injection sites of 6-OHDA in the PFC (solid circles, upper section). Injections were made successively at increasingly more ventral locations. The lower section shows the location of the electrochemical probes for animals that had previously received 6-OHDA lesions of the PFC (open symbols) or had PFC DA intact (solid symbols) and were tested each day with a highly palatable food (squares) or bedding from cages that housed estrus female rats (circles) (adapted from Paxinos and Watson, 1982).

lesioned (Lesion-Control, $n=6$ ) animals were placed, daily, in the recording chambers but were not exposed to either stimulus. Animals in these two groups were left in the recording chamber for $60 \mathrm{~min}$ and then returned to their home cages.

The 6-OHDA lesions resulted in a $89.6 \%( \pm 3.1)$ depletion of DA and $94 \%( \pm 2.8)$ depletion of DOPAC within the PFC. Concentrations of norepinephrine and 5-HT were not affected. The electrochemical probes for all animals were within the medial region of nAcc (see Fig. 1).

Basal electrochemical current. The analysis of the basal electrochemical current recorded after $20 \mathrm{~min}$ in the chamber revealed a significant effect of lesion $[F(1,21)=6.78, p<0.05]$. As shown in Figure 2, the resting oxidation current recorded prior to the day's testing was higher for the lesioned than the intact animals.

Rate of increase. The lesioned animals tested repeatedly with food showed a faster rate of increase in the electrochemical signal, and the difference increased across days (see Fig. 3). There was an effect oflesion $[F(1,11)=8.28, p<0.05]$, and a marginal lesion $\times$ day interaction $[F(5,55)=2.15, p=0.07]$. Simple 


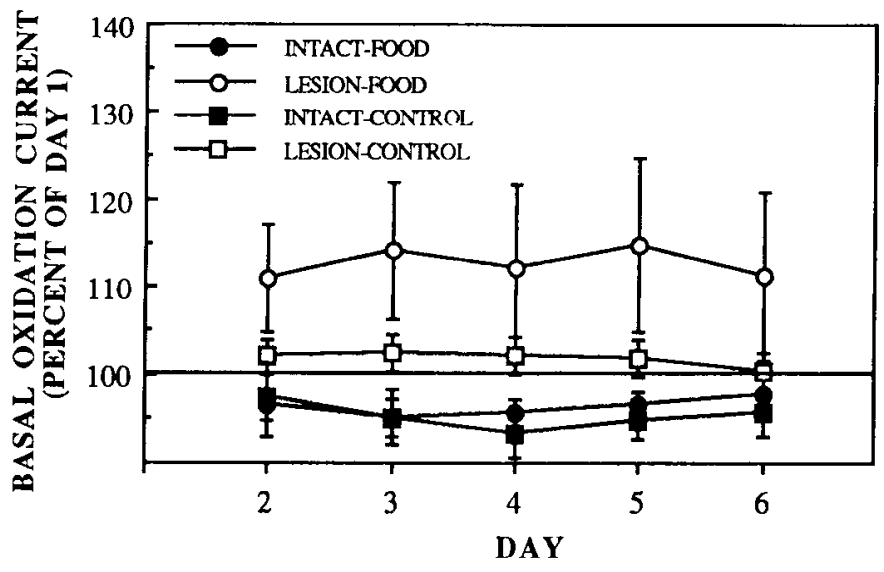

Figure 2. Basal oxidation current recorded after $20 \mathrm{~min}$ in the testing chamber prior to each test. Animals had previously received 6-OHDA lesions of the PFC (open symbols, LESION) or had PFC DA intact (solid symbols, INTACT) and were tested each day with a highly palatable food (circles, $F O O D$ ) or exposed only to the recording chamber (squares, CONTROL). Current is expressed as mean percentage $( \pm 1$ SEM) of the current on day 1 of testing.

effects analysis found that the rate of increase did not vary across days for the Intact-Food group $(p>0.1)$, but that among the Lesion-Food group, the rate of increase did vary across days $[F(5,55)=3.863, p<0.01]$. Furthermore, there was an effect of lesion on days 4 and 5 ( $p$ values $<0.05$ ), indicating that the difference between the groups was due to an increased rate of change among the lesioned animals on these days.

The analyses of the rate of increase in the electrochemical signal elicited by exposure to food indicated that the intact and lesioned animals displayed similar rates of increase on the first test with food, but that the electrochemical signal increased more rapidly in the lesioned animals after repeated testing.

Peak amplitude. The maximum amplitude of the stimuluselicited increase in the electrochemical signal was also analyzed. There were effects of day $[F(5,55)=2.48, p<0.05)]$ and lesion $[F(1,11)=5.42, p<0.05]$. The Lesion-Food group showed

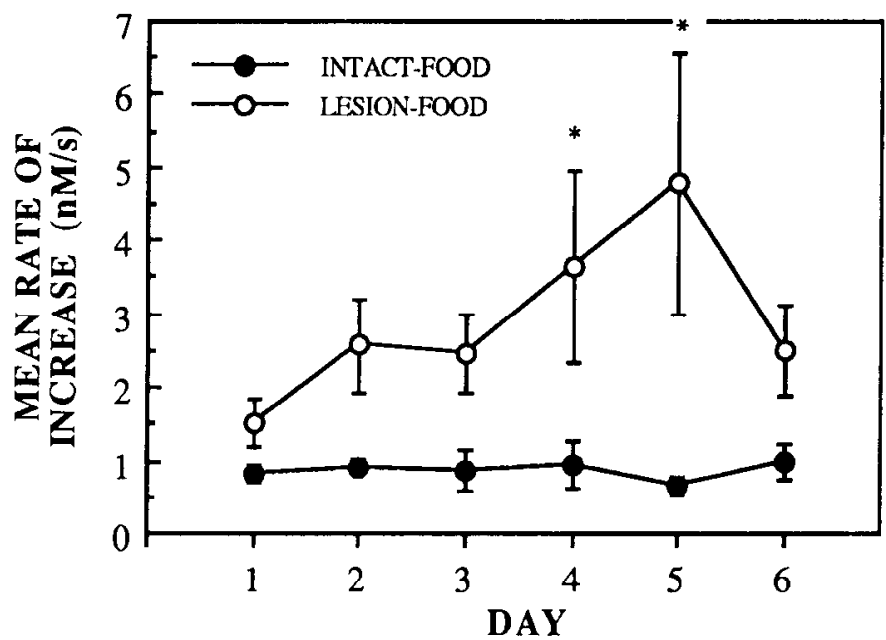

Figure 3. Mean ( \pm 1 SEM) rate of increase of the electrochemical signals recorded during eating for intact animals (INTACT-FOOD, solid circles) and animals that had previously received 6-OHDA lesions of the PFC (LESION-FOOD, open circles). *, different from the IntactFood group on the same day, $p<0.05$.

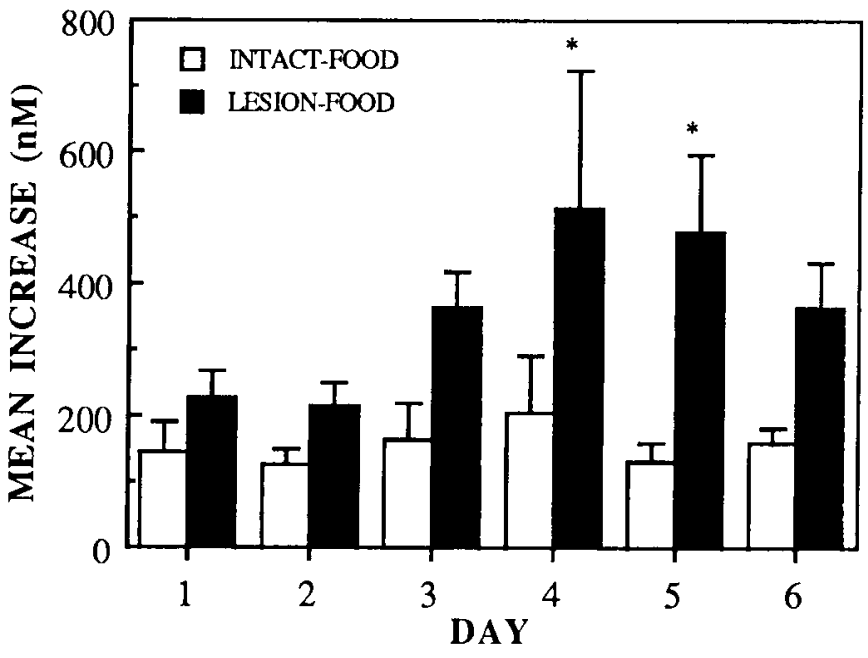

Figure 4. Mean (+1 SEM) maximum increase of electrochemical signals induced by eating among intact animals (INTACT-FOOD, open bars) and animals that had previously received 6-OHDA lesions of the PFC (LESION-FOOD, solid bars). *, different from the Intact-Food group on the same day, $p<0.05$.

larger increases than the Intact-Food group, and the peak amplitude increased across days. As can be seen in Figure 4, the effect of day can be attributed to an increase among the lesioned animals. Simple effects analysis confirmed that the effect of day was due to an increase in maximum amplitude across days for the lesioned group $[F(5,55)=3.84, p<0.01]$; the intact group did not vary significantly across days $(p>0.1)$. Furthermore, the effect of lesion was due to the Lesion-Food group showing a significantly greater change in the electrochemical signal than the Intact-Food group on days 4 and 5 . That is, intact animals given repeated exposure to food showed increases in the electrochemical signal that did not vary in amplitude across days, whereas animals with PFC 6-OHDA lesions showed increased food-elicited changes after repeated testing.

The Red:Ox ratio, calculated at the asymptote of the increase, did not differ between groups or across days ( $p$ values $>0.1$; see Table 1). Thus, although the electrochemical signal varied in rate of change and maximum amplitude as a function of lesion and repeated testing, the contributors to the electrochemical signal remained consistent.

Response to bedding. To investigate if repeated testing with food affected responsiveness to another naturally reinforcing stimulus, animals were also tested with bedding on days 1 and 6 . The rate of increase elicited by exposure to bedding did not differ between days, although there was an effect of lesion $[F(1,11)$ $=13.362, p<0.01]$. That is, when exposed to the bedding, the lesioned animals showed a faster rate of increase than did the intact animals, but the rate of increase was not influenced by the intervening experience with food. The amplitude of the bedding-elicited increase was not affected by repeated exposure to food.

\section{Sex-related olfactory cues}

Two groups of animals were tested with bedding obtained from cages that housed estrus female rats: intact animals (Intact-Bedding, $n=7$ ) and animals that had previously received 6-OHDA lesions of the PFC (Lesion-Bedding, $n=6$ ). All animals were tested with both food and bedding on the first and sixth test day. Groups of intact (Intact-Control, $n=6$ ) and lesioned (Le- 
Table 1. Mean ( \pm I SEM) Red : Ox ratio for the groups tested daily with a highly palatable food (Food) or sex-related olfactory cues (Bedding)

\begin{tabular}{|c|c|c|c|c|c|c|}
\hline \multirow[b]{2}{*}{ Group } & \multicolumn{6}{|l|}{ Day } \\
\hline & 1 & 2 & 3 & 4 & 5 & 6 \\
\hline Intact-Food & $0.78 \pm 0.12$ & $0.79 \pm 0.24$ & $0.62 \pm 0.11$ & $0.77 \pm 0.15$ & $0.68 \pm 0.10$ & $0.77 \pm 0.06$ \\
\hline Lesion-Food & $0.89 \pm 0.14$ & $0.72 \pm 0.11$ & $0.79 \pm 0.05$ & $0.92 \pm 0.14$ & $0.66 \pm 0.23$ & $0.73 \pm 0.15$ \\
\hline Intact-Bedding & $0.68 \pm 0.14$ & $0.76 \pm 0.14$ & $0.63 \pm 0.11$ & $0.77 \pm 0.10$ & $0.99 \pm 0.17$ & $0.61 \pm 0.08$ \\
\hline Lesion-Bedding & $0.71 \pm 0.12$ & $0.92 \pm 0.21$ & $0.58 \pm 0.08$ & $0.65 \pm 0.09$ & $0.79 \pm 0.05$ & $0.60 \pm 0.10$ \\
\hline
\end{tabular}

The Red : Ox ratio was calculated at the point that the increase in the electrochemical signal reached asymptote. The Red:Ox ratio for DA is $0.6-0.8$.

sion-Control, $n=6$ ) animals were tested without presentation of the bedding.

DA and DOPAC depletions were similar to those reported above for the animals in tests with food. There was a significant depletion of DA $(87 \% \pm 3.8)$, and depletion of DOPAC $(92.4 \%$ $\pm 3.2)$ within the prefrontal cortex. Concentrations of norepinephrine and 5-HT were not significantly affected. The electrochemical probes for all animals were within the nAcc (see rig. 1).

Basal electrochemical current. The analysis of the basal clcctrochemical current recorded prior to each day's test found significant effects of lesion $[F(1,21)=6.28, p<0.05]$, stimulus [control vs. bedding; $F(1,21)=6.68, p<0.05]$, and day $[F(4,84)$ $=5.13, p<0.01]$, as well as a lesion $\times$ day interaction $[F(4,84)$ $=6.39, p<0.01]$. Figure 5 presents the basal electrochemical currents across days. Simple effects analysis found that there was an effect of day among the bedding-exposed animals $[F(4,84)$ $=13.05, p<0.001]$ but not among the control groups $(p>$ $0.1)$, and that the effect of day was present among the lesioned animals $[F(4,84)=7.29, p<0.001]$ but not the intact animals $(p>0.1)$. That is, the effects of lesion and stimulus were due to an increase in the basal oxidation current among the LesionBedding group on days 4,5 , and 6 ( $p$ values $<0.01$ ).

Rate of increase. The analysis of the rate of increase, in $n \mathbf{m} /$ $\mathrm{sec}$, from the initial change in the electrochemical signal to the peak amplitude yielded a significant lesion $\times$ day intcraction $[F(5,55)=2.49, p<0.05]$; the effect of lesion did not quite

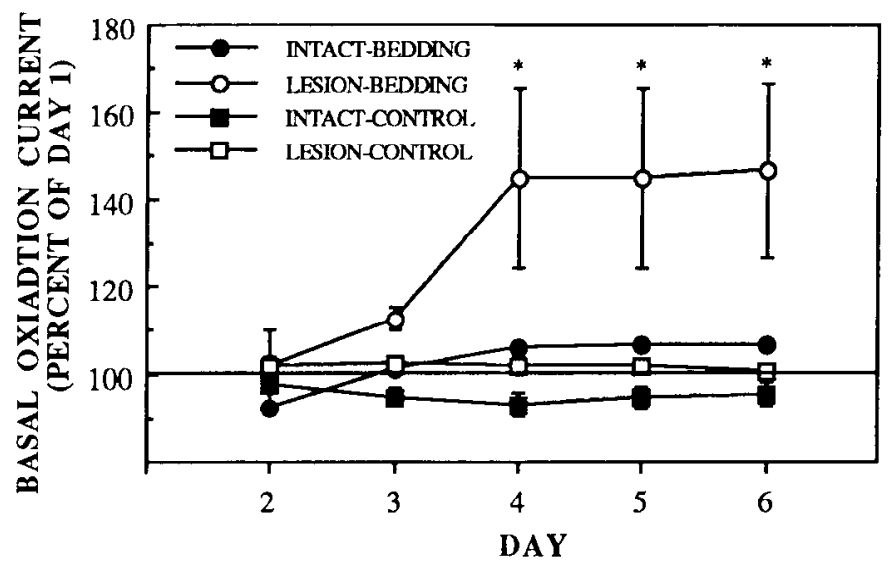

Figure 5. Basal oxidation current recorded after $20 \mathrm{~min}$ in the testing chamber prior to the beginning of each test. Animals had previously received 6-OHDA lesions of the PFC (open symbols, LESION) or had PFC DA intact (solid symbols, INTACT) and were tested each day with sex-related olfactory cues (circles, $B E D D I N G$ ) or exposed only to the recording chamber (squares, CONTROL). Current is expressed as mean percentage $( \pm 1$ SEM) of the current recorded on day 1 of testing. *, different from the intact groups on the same day, $p<0.05$. attain statistical significance $[F(1,11)=4.1, p<0.07]$. As shown in Figure 6, the lesioned animals showed a faster rate of change on days 4 and 6 than did the intact animals ( $p$ values $<0.01$ ).

Peak amplitude. Overall, there was a significant effect of lesion $[F(1,11)=7.07, p<0.05]$; the lesioned animals showed a larger response to the bedding than did the intact animals (see Fig. 7). Simple main effects analysis found that the effect of lesion was due to a significantly larger response by the lesioned animals on days 3 and 6 ( $p$ values $<0.05$ ). There was also an effect of day $[F(5,55)=2.95, p<0.05]$; both groups exposed to the estrus female bedding showed an enhanced response with experience. The Intact-Bedding group showed more than a doubling of the maximum increase by day 4 , and the Lesion-Bedding group an increase that had almost doubled in amplitude by day 3 . Examples of bedding-elicited electrochemical signals recorded in an intact and a lesioned animal on test days 1, 3, and 6 are shown in Figure 8.

The Red:Ox ratio, calculated.at the asymptote of the increase, did not vary significantly between intact and lesioned animals, or across days (see Table 1). The Red:Ox ratio indicates that the contributors to the electrochemical signal did not vary despite changes in basal oxidation current, rate, and amplitude.

Response to food. The two groups of animals repeatedly exposed to the bedding were also tested with food on days 1 and 6. None of the terms in the analyses of the rate of increase during exposure to food were statistically significant. The analysis of the maximum amplitude of the electrochemical signal

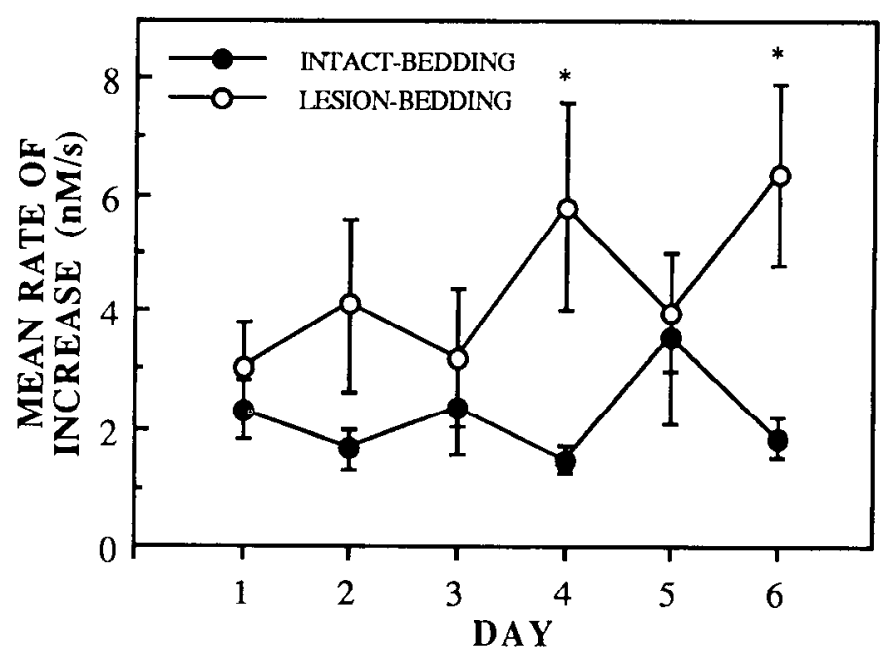

Figure 6. Mean ( \pm I SEM) rate of increase of the electrochemical signals during exposure to the bedding among intact animals (INTACT$B E D D I N G$, solid circles) and animals that had previously received 6-OHDA lesions of the PFC (LESION-BEDDING, open circles). *, different from the Intact-Bedding group on the same day, $p<0.05$. 


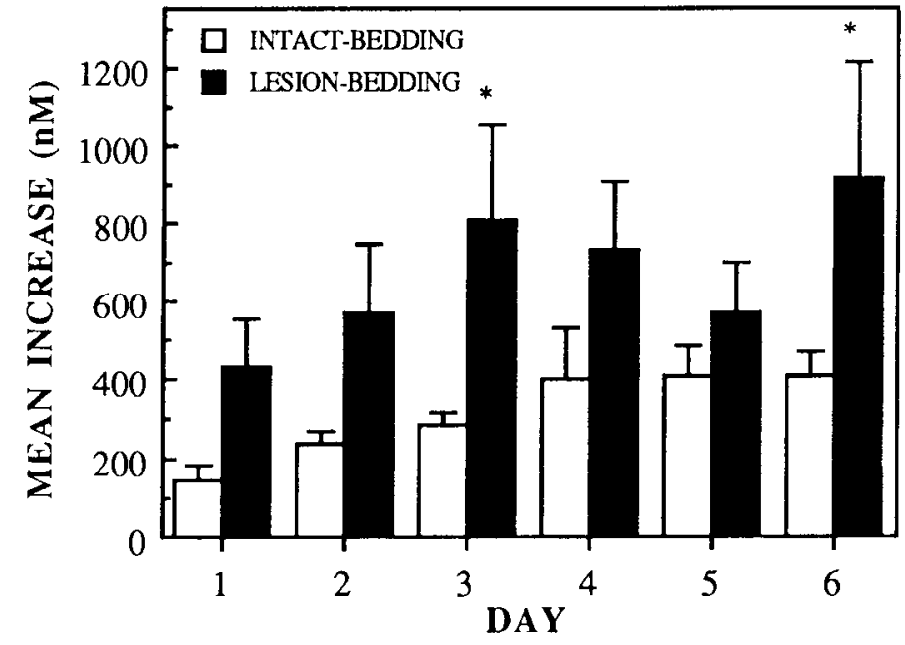

Figure 7. Mean (+1 SEM) maximum increase of the electrochemical signals induced by exploration of the bedding among intact animals (INTACT-BEDDING, open bars) and animals that had previously received 6-OHDA lesions of the PFC (LESION-BEDDING, solid bars). *, different from the Intact-Bedding group on the same day, $p<0.05$.

found only an effect of lesion $[F(1,11)=6.914, p<0.05]$. The lesioned animals displayed larger increases than did the intact animals, but the response to food was not influenced by repeated exposure to bedding.

\section{Discussion}

The results of these experiments indicate that both a highly palatable food and sex-related olfactory cues are able to elicit increases in the electrochemical signal recorded within the nAcc. If animals were tested with food, the amplitude and temporal characteristics of the response remained consistent across the 6 test days. Repeated exposure to the sex-related cues led to a progressively enhanced, or sensitized, response among intact animals. If, however, PFC DA was partially depleted, the response to food was enthanced; the rate of change and amplitude increased with repeated testing (see Figs. 3, 4). PFC DA depletions increased the amplitude of the response to the sex-related olfactory cues and resulted in a faster rate of increase on test days 4 and 6 (see Figs. 6-8).

In vivo electrochemical techniques, including chronoamperometry, do not positively identify the specific neurochemicals contributing to the electrochemical signal. Previous in vivo and in vitro studies using Nafion-coated electrodes and the sampling rate $(5 \mathrm{~Hz}$ ) used in the present experiments (Gratton et al., 1988, 1989), however, have found that the Red:Ox ratios provide a means of identifying the electroactive species interacting with the electrode. Using electrodes and sampling rate similar to those used in the present experiments, DA yields a Red:Ox ratio of 0.6-0.8; virtually all of the oxidized DOPAC is reduced (Red: $\mathrm{Ox}=0.9-1.0$ ), and the Red:Ox ratios for norepinephrine and 5 -HT are $0.4-0.5$ and $0.1-0.2$, respectively. Increases in the electrochemical signal concomitant with feeding or exploration of the estrus female bedding yielded a Red:Ox ratio within the range expected for DA, although the Red:Ox ratio on 4 of the 24 tests was somewhat higher than would be expected for DA (see Table 1). These results suggest that DA was the major contributor to the electrochemical signal, but that there may have been a contribution of the DA metabolite DOPAC. These results are consistent with the known neurochemical content of

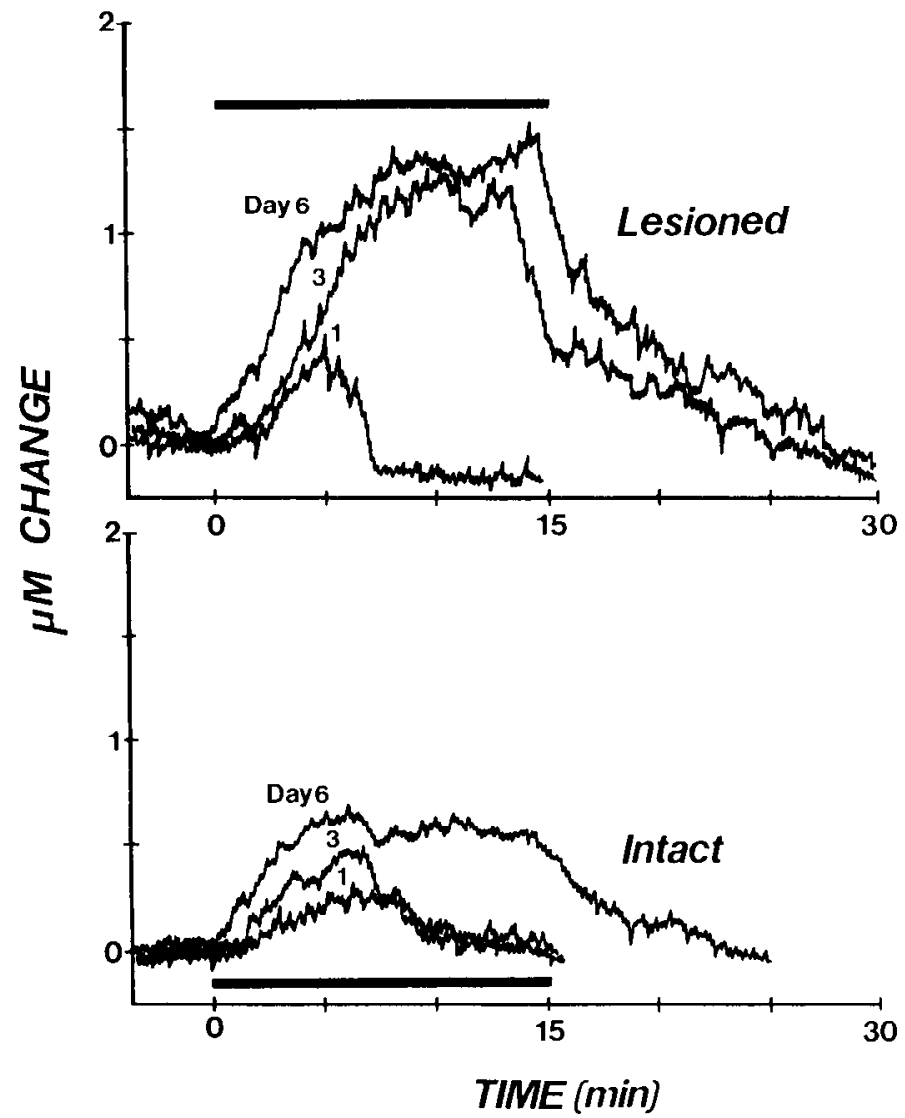

Figure 8. Examples of electrochemical signals recorded on test days 1,3 , and 6 from a lesioned (top) and an intact animal (bottom) in response to bedding. The data are expressed as micromolar change in dopamine concentration. Length of horizontal bar corresponds to duration of exposure to bedding.

the nAcc, a rich DA innervation with a comparatively sparser innervation by norepinephrine- and 5-HT-containing terminals. The Red:Ox ratios, the temporal contiguity of the changes in the electrochemical signal with the stimuli, and the electrochemical probes' relative insensitivity to anionic compounds, such as DOPAC, all suggest that the changes in the electrochemical signals are principally due to increases in the concentration of DA, and perhaps also DOPAC, at the electrode surface.

The resting oxidation current recorded when the animals were placed in the testing chambers increased across days, especially for the Lesion-Bedding groups. That is, as these animals gained experience with the stimuli in the test chamber, the oxidation current at the beginning of the day's test increased. Although these experiments were not designed to test for conditioned effects, the increase in the basal oxidation current during the first $20 \mathrm{~min}$ in the testing chamber, prior to that day's presentation of the stimulus, suggests that exposure to the test chamber itself increased the availability of electroactive compounds at the electrode surface. A conditioned release of DA has been reported for stimuli associated with repeated injections of opiates (see Schiff, 1982), and the data presented here suggest that stimuli associated with the presentation of a naturally reinforcing event can also increase the release of DA. That is, a specific environment associated with the presentation of stimuli that increase the extracellular concentrations of DA within the $\mathrm{nAcc}$ 
may, itself, acquire the ability to elicit mesolimbic DA release. It will be interesting to test explicitly the ability of conditioned stimuli to elicit mesocorticolimbic DA release.

Interestingly, Pycock and coworkers have reported increased turnover of DA within the nAcc of PFC DA-depleted animals (Carter and Pycock, 1980; Pycock et al., 1980), whereas more recent postmortem studies have failed to observe such changes (Rosin et al., 1987; Clark et al., 1988). Both of the expcrimcnts reported here found that initially the lesioned and intact animals had similar basal oxidation currents within the nAcc; differences between groups emerged only with repeated testing in the stimulus-associated environment. These findings suggest that the testing history of the animal and the environment in which the animal is killed may have an impact on putative "basal" concentrations of DA within the nAcc.

The electrochemical signal increased during the time that the animals were interacting with the stimuli used: increasing to a plateau during feeding or exploration of the bedding, and then returning to baseline after the food had all been consumed or the bedding removed from the testing chamber. While the animals were interacting with the stimuli and the electrochemical signal was increased above baseline, the behavior of the animals was focused on the stimuli; animals typically ate the pieces of food in quick succession or remained relatively immobilc whilc sniffing the bedding. In both cases, stimulus-directed behavior was mostly uninterrupted by ex ploration of the chamber or other behaviors, except for some sporadic grooming. Interestingly, the return of the electrochemical signal to baseline after the food had been consumed or bedding removed often coincided with a period of increased locomotor activity by the animal. These observations suggest that the increases in the electrochemical signal were due to the impact of the stimuli, and not to increased motor activity or other nonspecific factors. This interpretation is consistent with previous research that has indicated that mesolimbic DA is important in mediating the incentive-motivational properties of reinforcing stimuli (e.g., Blundell and Latham, 1978; Wise et al., 1978; Geary and Smith, 1985; Mitchell and Stewart, 1989; Mitchell and Gratton, 1991).

The stimuli used in the present experiment, a highly palatable food and sex-related olfactory cues, were both effective in increasing extracellular concentrations of DA. One important respect in which these stimuli differ is that interaction with the food evoked a consummatory response (feeding) whereas exposure to the bedding did not elicit a consummatory response. Both stimuli, however, are reinforcing: copulation without ejaculation and noncopulatory exposure to an estrus female are effective reinforcers in instrumental conditioning (Kagan, 1955; Whalen, 1961; Jowaisas et al., 1971), and food is well known to be an effective reinforcer in instrumental conditioning. Sexually active male rats show a preference for the odor of an estrus female (Carr et al., 1966; Lydell and Doty, 1972), and animals show a preference for stimuli associated with food. Thus, although eating a highly palatable food and exploration of sexrelated olfactory cues differ in the presence or absence of a consummatory response, among other dimensions such as sensory modality, both are reinforcing events. As discussed previously, copulation and exposure to sex-related cues (Mitchell and Stewart, 1989; Mas et al., 1990; Mitchell and Gratton, 1991) and feeding (Hernandez and Hoebel, 1988; Rose and Gratton, 1990; Mark et al., 1991) have been reported to increase DA and DA metabolite levels in the nAcc. Thus, these two reinforcing stimuli, regardless of their specific characteristics, activate the mesolimbic DA system leading to increased extracellular DA concentrations within the nAcc.

Among the intact animals, both of the stimuli used were capable of eliciting an increase in extracellular concentrations of DA on the first exposure, but an enhanced release occurred only with repeated exposure to the bedding; the intact animals repeatedly tested with food showed increases that did not vary predictably from day to day. It is not known why repeated presentation of the food did not lead to an enhanced release while the bedding did. It should be noted that intact and lesioned animals did not differ on day 1 on any measure, and yet lesioned animals repeatedly exposed to food showed evidence of a sensitized DA release on later tests. Thus, at least among lesioned animals, food-elicited releases were of sufficient magnitude and invoked elements necessary for sensitization to occur. It is possible that food activated pathways that interfered with the development of sensitization, such as the mesocortical DA system, and that sex-related cues have less of an impact on mesocortical DA (see below). The reason(s) why, among intact animals, repeated exposure to sex-related olfactory cues, but not food, can lead to increased activation of the mesolimbic DA system remains to be addressed in future experiments.

We have reported previously (Mitchell and Gratton, 1991) that sex-related olfactory cues elicited increased $D \Lambda$ concentrations within the $\mathrm{nAcc}$, but not at more dorsal nAcc sites or within the caudate-putamen, a terminal field of the nigrostriatal DA system. Food, however, has been reported to increase extracellular DA concentrations at nigrostriatal as well as mesolimbic terminal sites (Rose and Gratton, 1990). The effects of sexual incentive stimuli, therefore, appear to be specific to the mesolimbic DA system, but exposure to food, at least when eating is allowed, affects both the mesolimbic and nigrostriatal DA systems. It will be interesting to examine whether this difference is due to eating per se, or if there is indeed a difference in the pattern of activation within the forebrain DA terminals dependent on the specific incentive stimulus used.

Although the rate and amplitude of the food-elicited changes increased across days among the lesioned animals, the results of the test on the sixth day were similar to those obtained on the initial tests. It is not clear why there was a decrease in foodelicited DA release on day 6 . The response to the bedding, once increased, stayed elevated. It is possible that the potentiation of food-elicited DA release was temporary; however, results from other studies of sensitized DA release using stress, opiates, or pyschomotor stimulants all suggest that, once sensitized, the mesolimbic DA system remains hyperresponsive for as long as months (Robinson and Becker, 1986; Robinson et al., 1988). These findings, together with the more potent effects of the bedding, suggest that repeated exposure to natural stimuli may come to elicit persistent changes with sufficient experience, but that in the case of food among non-food-deprived animals, more experience may be necessary to sensitize the system.

The differences between the intact and lesioned animals suggests areas involved in the development of sensitization. Sensitization to the effects of a stimulus may be mediated, at least in part, by changes within the mesolimbic DA system, or within a PFC input to DA neurons that innervated $n A c c$. If the changes occur only with repeated activation of the mesolimbic DA system, then intact and lesioned animals should not differ in the development of sensitization. If PFC-mesolimbic DA interactions are involved, then lesioned animals should differ in the development of sensitized DA release in the nAcc. Lesioned 
animals tested with food showed evidence of sensitized DA release with repeated testing (see Figs. 3, 4). These differences in the effects of repeated food presentation between intact and lesioned animals indicate that the PFC is involved in the sensitization of $\mathrm{nAcc} D A$ release. Dopamine mainly inhibits unit activity in PFC (Gratton et al., 1987; Sesack and Bunney, 1989), and this region of cortex is thought to send excitatory amino acid-containing projections to subcortical structures, including the nAcc and ventral tegmental area (Christie et al., 1985a,b; Sesack et al., 1989). Thus, destruction of cortical DA may chronically disinhibit this excitatory input to the mesolimbic DA system. However, if simple disinhibition of this system is involved, then it might be expected that lesioned animals would show greatly amplified DA release, even on the initial exposure to the stimuli. Indeed, PFC DA depletion has been reported to potentiate the stimulant effect of acute stress on mesolimbic DA levels (Deutch et al., 1990). However, while DA release was amplified in response to an initial exposure to the bedding particularly, significant differences between the intact and lesioned animals emerged only with repeated testing, indicating that repeated activation of the mesolimbic DA system was required. Thus, an interaction between the PFC input to the mesolimbic DA system and DA release within the nAcc appears to be involved in the development of sensitized DA release elicited by naturally reinforcing stimuli. Corticostriatal glutamatergic neurons are involved in the presynaptic regulation of DA release from DA terminals within the striatum (Nieoullon et al., 1978; Romo et al., 1986). Glutamate increases the release of DA within the striatum via both quisqualate/kainate and NMDA receptors (Roberts and Anderson, 1979; Krebs et al., 1989; Barbeito et al., 1990), and NMDA receptors have been found on rat striatal synaptosomes (Krebs et al., 1991). Evidence also exists for glutamatergic control of DA release in nAcc; 6-OHDAinduced lesions cause a reduction of $\mathrm{PCP} / \mathrm{NMDA}$ receptor sites in nAcc (French et al., 1985), and lesions of PFC result in a reduction of high-affinity uptake of glutamate in this region (Carter, 1980; Walaas, 1981). Furthermore, NMDA, kainate, and quisqualate have been shown to stimulate radiolabeled DA release in nAcc (Marien et al., 1983; Jones et al., 1987). These findings indicate that glutamatergic projections can act on DA nerve terminals to modulate DA release. However, mesocortical DA could also be acting on PFC efferents to the DA cell bodies region in the ventral mesencephalon, where microinjections of NMDA and kainate have been shown to increase DA metabolism in PFC and nAcc, respectively (Kalivas et al., 1989). Mechanisms in the DA cell body region are thought to be important in the development of sensitization to psychomotor stimulants (Stewart and Vezina, 1989) and opiates (Vezina and Stewart, 1984; Kalivas and Duffy, 1987), and PFC glutamatergic projections to this region may be important in modulating the development of sensitized DA release elicited by naturally occurring stimuli. It is interesting to note in this context the widespread role that glutamate plays in mediating synaptic plasticity within the CNS (see Monaghan et al., 1989, for a recent review).

In conclusion, the present results indicate that the DA projection to PFC normally acts to dampen the reactivity of the mesolimbic DA system to environmental stimuli. These results also provide neurophysiological evidence in support of current hypotheses concerning the role of cortical mechanisms in the functional hyperactivity of subcortical DA systems associated with psychosis (see Grace, 1991).

\section{References}

Adler M (1961) Changes in sensitivity to amphetamine in rats with chronic brain lesions. J Pharmacol Exp Ther 134:214-224.

Babbini M, Gaiardi M, Bartoletti M (1975) Persistence of chronic morphine effects upon activity in rats 8 months after ceasing treatment. Neuropharmacology 14:611-614.

Barbeito L, Cheramy A, Godeheu G, Desce JM, Glowinski J (1990) Glutamate rcceptors of a quisqualate-kainate subtype are involved in the presynaptic regulation of dopamine release in the cat caudate nucleus in vivo. Eur J Neurosci 2:304-311.

Beckstead RM (1979) An autoradiographic examination of corticocortical and subcortical projections of the mediodorsal-projection (prefrontal) cortex in the rat. J Comp Neurol 184:43-62.

Bjorklund A, Lindvall $O$ (1984) Dopamine-containing systems in the CNS. In: Handbook of chemical neuroanatomy, Vol 2, Classical transmitters in the CNS (Bjorklund A, Hokfelt T, eds), pp 55-122. Amsterdam: Elsevier.

Blundell JE, Latham CJ (1978) Pharmacological manipulation of food and water intake. In: Chemical influences on behavior (Iversen LL, Iversen SD, Snyder SH, eds), pp 201-254. London: Academic.

Butcher LL, Butcher SG, Larsson K (1969) Effects of apomorphine, (+)-amphetamine, and nialimide on tetrabenazine-induced suppression of sexual behavior in the male rat. Eur J Pharmacol 7:283-288.

Caggiula AR, Hoebel BG (1966) "Copulation-reward site" in the posterior hypothalamus. Science 153:1284-1285.

Caggiula AR, Shaw DH, Antelman SM, Edwards DJ (1976) Interactive effects of brain catecholamines and variations in sexual and nonsexual arousal on copulatory behavior of male rats. Brain Res 111 : 321-336.

Carlson JN, Herrick KF, Baird JL, Glick SD (1987) Selective enhancement of dopamine utilization in the rat prefrontal cortex by food deprivation. Brain Res 400:200-203.

Cart WJ, Loeb LS, Wylie NR (1966) Responses to feminine odors in normal and castrated male rats. J Comp Physiol Psychol 62:336-338.

Carter CJ (1980) Glutamatergic pathways from medial pre-frontal cortex to the anterior striatum, nucleus accumbens and substantia nigra. Br J Pharmacol 70:50-51.

Carter CJ, Pycock CJ (1980) Behavioral and biochemical effects of dopamine and noradrenaline depletion within the medial prefrontal cortex of the rat. Brain Res 192:163-176.

Christie MJ, Bridge S, James LB, Beart PM (1985a) Excitotoxin lesions suggest an aspartatergic projection from rat prefrontal cortex to ventral tegmental area. Brain Res 333:169-172.

Christie MJ, Bridge S, James LB, Beart PM (1985b) An excitant amino acid projection from medial prefrontal cortex to the anterior part of nucleus accumbens in the rat. J Neurochem 45:477-482.

Clark WA, Roth RH, Deutch AY (1988) Effects of dopamine depletion of the prefrontal cortex on stress-induced changes in mesolimbic and striatal dopamine function. Soc Neurosci Abstr 14:1214.

Cox VC, Valenstein ES (1969) Distribution of hypothalamic sites yielding stimulus-bound behavior. Brain Behav Evol 2:359-376.

Deutch AY, Clark WA, Roth RH (1990) Prefrontal cortical dopamine depletion enhances the responsiveness of mesolimbic dopamine neurons to stress. Brain Res 521:311-315.

Doherty M, Gratton A (1991) Behavioral evidence of depolarization block of mesencephalic dopamine neurons by acute haloperidol in partially 6-hydroxydopamine-lesioned rats. Behav Neurosci 105:579_ 587.

Eibergen RD, Caggiula AR (1973) Ventral midbrain involvement in copulatory behavior of the male rat. Physiol Behav 10:435-441.

Evans KR, Vaccarino FJ (1986) Intra-nucleus accumbens amphetamine: dose-dependent effects on food intake. Pharmacol Biochem Behav 25:1149-1151.

Foreman MM, Hall JL (1987) Effects of D2-dopaminergic receptor stimulation on male rat sexual behavior. J Neural Transm 68:153170

French ED, Pilapil C, Quirion R (1985) Phencyclidine binding sites in the nucleus accumbens and phencyclidine-induced hyperactivity are decreased following lesions of the mcsolimbic dopamine system. Eur J Pharmacol 116:1-9.

Geary N, Smith GP (1985) Pimozide decreases the positive reinforcing effect of sham-fed sucrose in the rat. Pharmacol Biochem Behav 22: $787-790$. 
Gerhardt GA, Oke AF, Nagy G, Modhaddam B, Adams RN (1984) Nafion-coated electrodes with high selectivity for CNS electrochemistry. Brain Res 290:390-395.

Gerhardt GA, Rose GM, Hoffer BJ (1986) Release of monoamines from striatum of rat and mouse evoked by local application of potassium: evaluation of a new in vivo electrochemical technique. J Neurochem 46:842-850.

Glickman SE, Schiff BB (1969) A biological theory of reinforcement. Psychol Rev 74:81-109.

Grace AA (1991) Phasic versus tonic dopamine release and the modulation of dopamine system responsivity: a hypothesis for the etiology of schizophrenia. Ncuroscicnce 41:1-24.

Gratton A, Wise RA (1988) Comparisons of connectivity and conduction velocities for medial forebrain bundle fibers subserving stimulation-induced feeding and brain stimulation reward. Brain Res 438 : $264-270$

Gratton A, Hoffer BJ, Freedman R (1987) Electrophysiological effects of phencyclidine in the medial prefrontal cortex of the rat. Neuropharmacology 26:1275-1283.

Gratton A, Hoffer BJ, Gerhardt GA (1988) Effects of electrical stimulation of brain reward sites on release of dopamine in rat: an in vivo electrochemical study. Brain Res Bull 21:319-324.

Gratton A, Hoffer BJ, Gerhardt GA (1989) In vivo electrochemical studies of monoamine release in the medial prefrontal cortex of the rat. Neuroscience 29:57-64.

Gysling K, Wang RY (1983) Morphinc-induced activation of A10 dopamine neurons in the rat. Brain Res 277:119-127.

Hamilton ME, Bozarth MA (1988) Feeding elicited by dynorphin 113 microinjections into the ventral tegmental area in rats. Life Sci 43:941-946.

Hernandez L, Hoebel BG (1988) Feeding and hypothalamic stimulation increase dopamine turnover in the accumbens. Physiol Behav 44:599-606.

Iversen SD (1971) The effect of surgical lesions to frontal cortex and substanta nigra on amphetamine responses in rats. Brain Res 31:295311

Jenck F, Gratton A, Wise RA (1986) Opposite effects of ventral tegmental and periaqueductal gray morphine injections on lateral hypothalamic stimulation-induced feeding. Brain Res 399:24-32.

Jones SM, Snell LD, Johnston KM (1987) Inhibition by phencyclidinc of excitatory amino acid-stimulated release of neurotransmitters in the nucleus accumbens. Neuropharmacology 26:173-179.

Jowaisas D. Taylor J. Dewsbury DA, Malagodi EF (1971) Copulatory behavior of males rats under an imposed operant requirement. Psychonomic Sci 25:287-290.

Kagan J (1955) Differential reward value of incomplete and complete sexual behavior. J Comp Physiol Psychol 48:59-64.

Kalivas PW, Duffy P (1987) Sensitization to repeated morphine injection in the rat: possible involvement of $\mathrm{A} 10$ dopamine neurons. $\mathrm{J}$ Pharmacol Exp Ther 241:204-212.

Kalivas PW, Widerlov E, Stanley D, Breese G, Prange AJ Jr (1983) Enkephalin action on the mesolimbic system: a dopamine-dependent and a dopamine-independent increase in locomotor activity. J Pharmacol Exp Ther 227:229-237.

Kalivas PW, Taylor S, Miller JS (1985) Sensitization to repeated enkephalin administration into the ventral tegmental area of the rat. I. Behavioral characterization. J Pharmacol Exp Ther 235:537-543.

Kalivas PW, Duffy P, Barrow J (1989) Regulation of the mesocorticolimbic dopamine system by glutamic acid receptor subtypes. J Pharmacol Exp Ther 251:378-387.

Krebs MO, Kemel ML, Gauchy C, Desban M, Glowinski J (1989) Glycine potentiates the NMDA-induced release of dopamine through a strychnine-insensitive site in the rat striatum. Eur J Pharmacol 166: $567-570$

Krcbs MO, Desce JM, Kemel ML, Gauchy C, Godeheu G, Cheramy A, Glowinski J (1991) Glutaminergic control of dopamine release in the rat striatum: Evidence for presynaptic NMDA receptors on dopaminergic nerve terminals. J Neurochern 56:81-85.

Kuczenski R (1983) Biochemical actions of amphetamine and other stimulants. In: Stimulants: neurochemical, behavioral and clinical perspectives (Creese I, ed), pp 31-6 I. New York: Kaven.

Louilot A, Le Moal M, Simon H (1989) Opposite influences of dopaminergic pathways to the prefrontal cortex or the septum on the dopaminergic transmission in the nucleus accumbens. An in vivo voltammetric study. Neuroscience 29:45-56.
Lydell K, Doty RL (1972) Male rat odor preferences for female urine as a function of sexual experience, urine age, and urine source. Horm Behav 3:205-212.

Lynch GS, Ballantine P, Campbell BA (1969) Potentiation of behavioral arousal after cortical damage and subsequent recovery. Exp Neurol 23:195-206.

Malmnas CO (1973) Dopaminergic reversal of the decline after castration of rat copulatory behavior. J Endocrinol 73:187-188.

Malmnas CO (1976) The significance of dopamine versus other catecholamines, for L-dopa induced facilitation of sexual behavior in the castrated male rat. Pharmacol Biochem Behav 4:521-526.

Malmnas CO (1977) Dopaminergic reversal of the decline after castration of rat copulatory behavior. J Endocrinol 73:187-188.

Marien M, Brien J, Jhamandas K (1983) Regional release of $\left[{ }^{3} \mathrm{H}\right]$ dopamine from rat brain in vitro: effects of opioids on release induced by potassium, nicotine and L-glutamic acid. Can J Physiol Pharmacol $61: 43-60$

Mark GP, Blander DS, Hoebel BG (1991) A conditioned stimulus decreases extracellular dopamine in the nucleus accumbens after the development of a learned taste aversion. Brain Res 551:308-310.

Mas M, Gonzalez-Mora JL, Louilot A, Sole C, Guadalupe T (1990) Increased dopamine release in the nucleus accumbens of copulating male rats as evidenced by in vivo voltammetry. Neurosci Lett 110 303-308.

Mitchell JB, Gratton A (1991) Opioid modulation and sensitization of dopamine release elicited by sexually relevant stimuli: a high-speed chronoamperometric study in freely behaving rats. Brain Res 551: 20-27.

Mitchell JB, Stewart J (1989) Effects of castration, steroid replacement, and sexual experience on mesolimbic dopamine and sexual behaviors in the male rat. Brain Res 491:116-127.

Mitchell JB, Stewart J (1990) Facilitation of sexual behaviors in the male rat associated with intra-VTA injections of opiates. Pharmacol Biochem Behav 35:643-649.

Monaghan DT, Bridges RJ, Cotman CW (1989) The excitatory amino acid receptors: their classes, pharmacology, and distinct properties in the function of the central nervous system. Annu Rev Pharmacol Toxicol 29:365-402.

Mucha RF, Iversen SD (1986) Increased food intake after opioid microinjection into nucleus accumbens and ventral tegmental area of rat. Brain Res 397:214-224.

Myers JL (1979) Fundamentals of experimental design, 3d ed. Boston: Allyn and Bacon.

Nagy G, Gerhardt GA, Oke AF, Rice ME, Adams RN, Moore RB, Szentirmay MN, Martin CR (1985) Ion exchange and transport of neurotransmitters in Nafion films on conventional and microelectrode surfaces. J Electroanal Chem 188:85-94.

Nieoullon A, Cheramy A, Glowinski J (1978) Release of dopamine evoked by electrical stimulation of the motor and visual areas of the cerebral cortex in both caudate nuclei and in the substantia nigra in the cat. Brain Res 145:69-83.

Olds ME (1990) Enhanced dopamine receptor activation in accumbens and frontal cortex has opposite effects on medial forebrain bundle self-stimulation. Neuroscicncc 35:313-325.

Palkovits M, Brownstein MJ (1988) Maps and guide to microdissection of the rat brain. New York: Elsevier.

Paxinos G, Watson C (1982) The rat brain in stereotaxic coordinates. New York: Academic.

Peris J, Zahniser NR (1987) One injection of cocaine produces a longlasting increase in $\left[{ }^{3} \mathrm{H}\right]$-dopamine release. Pharmacol Biochem Behav 27:533-535.

Pfaus J, Newton T, Blaha C, Fibiger H, Phillips A (1989) Electrochemical detection of central dopamine efflux during sexual activity in male rats. Soc Neurosci Abstr 15:558.

Post RM (1980) Intermittent versus continuous stimulation: effects of time interval on the development of sensitization or tolerance. Life Sci 26:1275-1282.

Pycock CJ, Kerwin RW, Carter CJ (1980) Effect of 6-hydroxydopamine lesions of the medial prefrontal cortex on neurotransmitter systems in subcortical sites in the rat. J Neurochem 34:91-99.

Roberts PJ, Anderson SD (1979) Stimulatory effect of L-glutamate and related amino acids on ${ }^{3} \mathrm{H}$-dopamine release from rat striatum: an in vivo model for glutamate actions. J Neurochem 32:1539-1545.

Robinson TE, Becker JB (1986) Enduring changes in brain and behavior produced by chronic amphetamine administration: a review 
and evaluation of animal models of amphetamine psychosis. Brain Res Rev 11:157-198.

Robinson TE, Jurson PA, Bennett JA, Bentgen KM (1988) Persistent sensitization of dopamine neurotransmission in ventral striatum (nucleus accumbens) produced by past experience with $(+)$-amphetamine: a microdialysis study in freely behaving rats. Brain Res 462 : 211-222.

Romo R, Cheramy A, Godeheu G, Glowinski J (1986) In vivo presynaptic control of dopamine release in the cat caudate nucleus. III. Further evidence for the implication of corticostriatal glutaminergic neurons. Neuroscience 19:1091-1099.

Rose GM, Gratton A (1990) Eating behavior is accompanied by dopamine release in medial striatum. Soc Neurosci Abstr 16:437.

Rosin DL, Deutch AY, Roth RH (1987) Alterations in subcortical dopaminergic function following dopaminc depletion in the medial prefrontal cortex. Soc Neurosci Abstr 13:1364.

Schiff SR (1982) Conditioned dopaminergic activity. Biol Psychiatry 17:135-154.

Sesack SR, Bunney BS (1989) Pharmacological characterization of the receptors mediating electrophysiological responses to dopamine in the rat medial prefrontal cortex: a microiontophoretic study. J Pharmacol Exp Ther 248:1323-1333.

Sesack SR, Deutch AY, Roth RH, Bunney BS (1989) Topographical organization of the efferent projections of the medial prefrontal cortex in the rat: an anterograde tract-tracing study with Phaseolus vulgaris leucoagglutinin. J Comp Neurol 290:213-242.

Spence SJ, Silverman JA, Corbett D (1985) Cortical and ventral tegmental systems exert opposing influences on self-stimulation from the prefrontal cortex. Behav Brain Res 17:117-124.
Stcwart J, Vezina P (1989) Microinjection of SCII-23390 into the ventral tegmental area and substantia nigra pars reticulata attenuate the development of sensitization to the locomotor activating effects of systemic amphetamine. Brain Res 495:401-406.

Ungerstedt U (1971) Aphagia and adipsia after 6-hydroxydopamine induced degeneration of the nigrostriatal dopamine system. Acta Physiol Scand [Suppl] 367:95-122.

Vaughan E, Fisher AE (1962) Male sexual behavior induced by intracranial electrical stimulation. Science 137:758-760.

Vezina P, Stewart J (1984) Conditioning and place-specific sensitization of increases in activity induced by morphine in the VTA. Pharmacol Biochem Behav 20:925-934.

Walaas I (1981) Biochemical evidence for overlapping neocortical and allocortical glutamate projections to the nucleus accumbens and rostral caudatoputamen in the rat brain. Neuroscience 6:399-405.

Whalen RE (1961) Effects of mounting without intromission and intromission without ejaculation on sexual behavior and maze learning. J Comp Physiol Psychol 54:409-415.

Winer BJ (1971) Statistical principles in experimental design, 2d ed. New York: McGraw-Hill.

Wise RA, Spindler J, DeWit H, Gerber GJ (1978) Neuroleptic-induced 'anhedonia' in rats: pimozide blocks the reward quality of food. Science 201:262-264.

Wise RA, Fotuhi M, Colle LM (1989) Facilitation of feeding by nucleus accumbens amphetamine injections: latency and speed measures. Pharmacol Biochem Behav 32:769-772. 